\title{
Pembuatan Robot Penjejak Dinding Dan Pemadam Api Otomatis Menggunakan Metode Fuzzy
}

\author{
Lilik Nur Kholida ${ }^{1}$, Agus Pramono ${ }^{2}$ \\ ${ }^{1}$ Sekolah Tinggi Teknologi Cahaya Surya Kediri \\ ${ }^{2}$ Sekolah Tinggi Teknologi Cahaya Surya Kediri \\ E-mail: liliknur.kholida28@gmail.com ${ }^{1}$, agpramono@gmail.com²
}

\begin{abstract}
ABSTRAK
Kecerdasan buatan merupakan bidang ilmu yang baru berkembang pada tahun 90-an dan pengaplikasiannya sudah banyak diterapkan dalam berbagai bidang, mulai dari game komputer, sistem kontrol otomatis, bidang robotika hingga sampai pada pemecahan masalah bidang ekonomi dan lain-lain. Pada bidang robotik juga, kecerdasan buatan banyak diaplikasikan pada robot-robot tertentu yang tujuan pembuatannya adalah untuk menyelesaikan suatu permasalahan. Sebagai contoh musibah kebakaran yang sering terjadi telah menimbulkan banyak korban jiwa dan kerugian harta benda. Untuk itu penulis membuat robot penjejak dinding dan pemadam api otomatis menggunakan metode fuzzy, yang diharapkan dapat dikembangkan lagi dan diterapkan secara langsung, agar dapat membantu dalam penyelesaian masalah tersebut. Robot ini dilengkapi dengan Arduino Uno, driver motor L298N dan motor DC, sensor ultrasonik dan flame sensor. Seluruh komponen dirangkai dan diintegrasikan dengan metode yang diterapkan pada program.
\end{abstract}

Kata Kunci : Arduino Uno, Metode Fuzzy Logic, Wall Follower, Pemadam Api. 


\begin{abstract}
Artificial intelligence is a field of science that just developed in the $90 \mathrm{~s}$ and its application has been widely applied in various fields, ranging from computer games, automatic control systems, to the field of robotics to arrive at solving economic problems and others. In the field of robotics as well, artificial intelligence is widely applied to certain robots whose purpose is to solve a problem. For example, frequent fire accidents have caused many casualties and property losses. For this reason, the authors make wall tracking robots and automatic fire extinguishers use the fuzzy method, which is expected to be further developed and applied directly, in order to assist in solving the problem. This robot is equipped with Arduino Uno, L298N motor driver and DC motor, ultrasonic sensors and flame sensors. All components are assembled and integrated with the methods applied to the program.
\end{abstract}

Keywords : Arduino Uno, Fuzzy Logic Method, Wall Follower, Fire Extinguisher. 


\section{PENDAHULUAN}

Kecerdasan buatan merupakan bidang ilmu yang baru berkembang pada tahun 90-an dan pengaplikasiannya sudah banyak diterapkan dalam berbagai bidang, mulai dari game komputer, sistem kontrol otomatis, bidang robotika hingga sampai pada pemecahan masalah bidang ekonomi dan lain-lain. "Beberapa tahun terakhir ini perkembangan teknologi di bidang robotika telah menjadi perhatian yang cukup serius. Hal ini terutama pada peran robot yang dapat menggantikan pekerjaan manusia terutama dalam lingkungan yang berbahaya, seperti daerah radiasi, kebakaran, penjelajahan ruang angkasa, penjinak bom dan lain-lain" [1]. Pada bidang robotik juga, kecerdasan buatan banyak diaplikasikan pada robot-robot tertentu yang tujuan pembuatannya adalah untuk menyelesaikan suatu permasalahan.

Sebagai contoh musibah kebakaran yang sering terjadi telah menimbulkan banyak korban jiwa dan kerugian harta benda. Terdapat resiko yang harus ditanggung oleh tim pemadam kebakaran pada saat memadamkan api di dalam suatu ruangan seperti tertimpa benda yang jatuh dari atap bangunan atau kebakaran yang semakin membesar. Berdasarkan contoh sederhana tersebut, "Robot jenis wall follower dan fire service dapat diaplikasikan sebagai bentuk penyelesaian masalah di atas yaitu khususnya pada sistem navigasi dan pencarian posisi api. Untuk menghasilkan navigasi yang efisien dalam mencapai target titik api yang akan dipadamkan dengan memanfaatkan jalur dari dinding bangunan tersebut" [2].

Rumusan Masalah yang akan dibahas adalah bagaimana membuat mekanisme dan mengintegrasikan sistem pada robot yang dapat bergerak mengikuti alur dinding dan dapat memadamkan api serta bagaimana menerapkan metode Fuzzy untuk mengontrol robot yang tidak memiliki sistem navigasi sama sekali agar dapat bergerak dengan baik.

Batasan penelitian yang akan dibahas adalah tentang pembuatan dan perancangan robot ini yang akan dipakai untuk pengendalian sistem robot adalah Mikrokontroler Atmel Mega 328P sebagai otak robot, L298 sebagai driver motor, motor DC sebagai penggerak roda dan kipas pemadam, flame sensor dan sensor ultrasonik sebagai inputan robot, serta menggunakan metode Fuzzy untuk memetakan ruang input ke dalam ruang output sehingga menghasilkan putaran keluaran/output yang dapat diatur menggunakan rule/aturan yang ditentukan program dari user. Pada pengendalian 
kontrol motor DC, fuzzyfikasi mampu menggerakkan motor dengan putaran halus sehingga bermanfaat untuk efisiensi penggunaan catu daya dan efektivitas pergerakan robot serta membahas hasil pengujian komponen dan pergerakan robot menggunakan software Arduino IDE.

Tujuan dilakukannya penelitian ini adalah untuk membuat mekanisme dan mengintegrasikan sistem pada robot yang dapat bergerak mengikuti alur dinding dan dapat memadamkan api serta menerapkan metode Fuzzy untuk mengontrol robot yang tidak memiliki sistem navigasi sama sekali agar dapat bergerak dengan baik.

Manfaat yang bisa didapat dalam penelitian ini antara lain mengetahui cara kerja sistem pada robot yang dapat mengikuti alur dinding menggunakan sensor api dan sensor ulrasonik berbasis Mikrokontroler serta mempelajari dan menerapkan algoritma Fuzzy untuk mengontrol robot yang tidak memiliki sistem navigasi sama sekali agar dapat bergerak dengan baik.

\section{METODE PENELITIAN}

Metode yang digunakan dalam penulisan laporan ini adalah dengan melakukan wawancara dengan orang-orang yang memiliki pengetahuan tentang permasalahan yang akan dibahas. Melakukan studi langsung ke toko yang menyediakan komponen dan alat-alat yang berkenaan dalam pembuatan project. Selain itu penulis melakukan studi literatur baik itu dari media cetak, media elektronik maupun jurnal-jurnal untuk mendapatkan referensi cara penulisan laporan dan penjelasan serta kegunaan komponen-komponen yang dibutuhkan dalam penyelesaian projek.

Sedangkan untuk penelitian, penulis menggunakan metode logika fuzzy. Metode ini diperkenalkan oleh Takagi-Sugeno Kang pada tahun 1985. Metode fuzzy sugeno merupakan metode inferensi fuzzy untuk aturan yang direpresentasikan dalam bentuk IF - THEN. Fuzzy Logic atau Logika Fuzzy adalah peningkatan dari logika Boolean yang mengenalkan konsep kebenaran sebagian. Pada logika klasik Boolean dinyatakan bahwa segala hal dapat diekspresikan dalam istilah binary (0 atau 1, benar atau salah, hitam atau putih, true atau false, ya atau tidak). Fuzzy logic memungkinkan nilai keanggotaan antara 0 dan 1, tingkat keabuan dan juga hitam dan putih, dan dalam bentuk linguistik, konsep tidak pasti seperti “sedikit", "lumayan" dan "sangat" [3]. 
Dengan adanya sistem kontrol seperti fuzzy logic ini, perilaku robot akan semakin dinamis dengan adanya istilah tingkat keabuan dalam fuzzy logic itu sendiri. Robot tidak lagi hanya mengenal istilah 0 dan 1 ata ya dan tidak, robot akan terlihat lebih cerdas dalam berbagai kondisi yang akan dibuat.

Tahapan dalam fuzzy logic secara umum terdapat 3 proses yaitu fuzzyfikasi, inferensi dan defuzzyfikasi.

\subsection{Fuzzyfikasi}

Dalam perancangan fuzzy logic pada Robot Pemadam Api ini terdapat dua masukan yang didapat dari hasil pengukuran sensor jarak depan dan sensor jarak samping kiri. Keanggotaan untuk sensor jarak depan dan sensor jarak samping kiri ditunjukkan pada Gambar 2.1. dan Gambar 2.2. berikut.

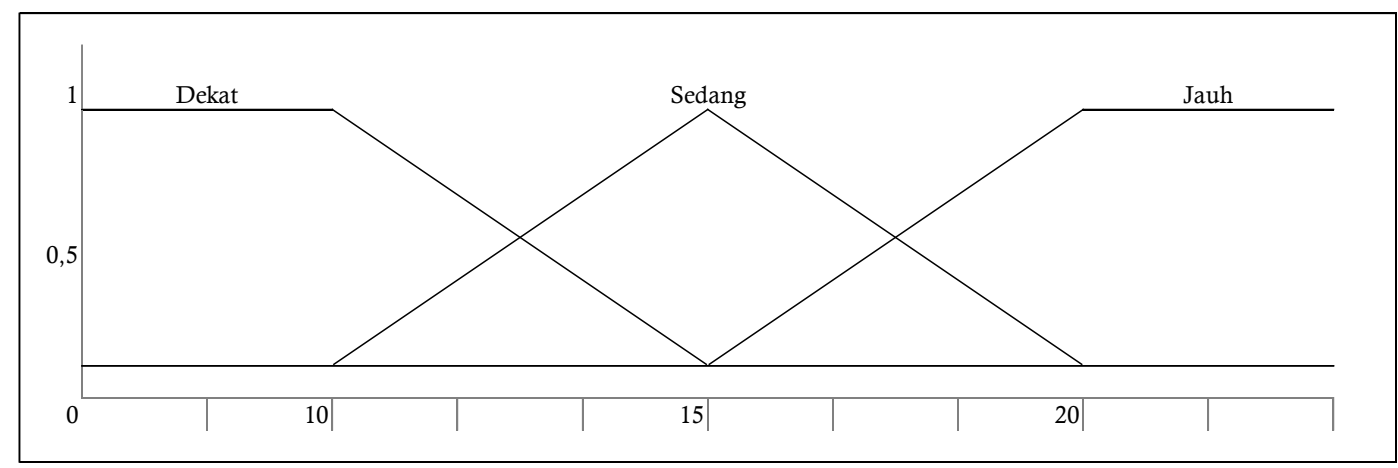

Gambar 2.1 Keanggotaan sensor jarak depan.

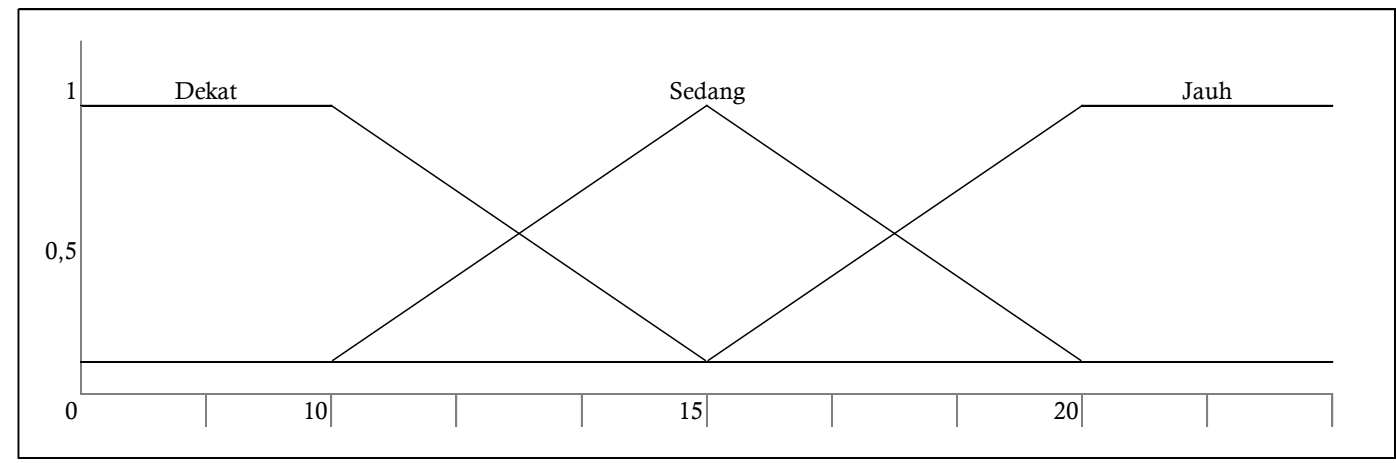

Gambar 2.2 Keanggotaan sensor jarak samping kiri. 
Rumus Fuzzyfikasi berdasarkan kurva keanggotaan di atas adalah sebagai berikut :

$$
\begin{aligned}
& \mu \text { sam_dekat }(x)\left\{\begin{array}{r}
1, x \leq 4 \\
6,4 \leq x \leq 10 \\
0, x \geq 16
\end{array}\right\} \\
& \mu_{\text {sam_sedang }(x)}\left\{\begin{array}{cc}
\frac{x-4}{6} & 0, x \leq 4 \\
\frac{16-x}{6} & 10 \leq x \leq 10 \\
0, x \geq 16
\end{array}\right\} \\
& \mu \text { sam_jauh(x) }\left\{\begin{array}{r}
0, x \leq 10 \\
\frac{x-10}{6}, 4 \leq x \leq 16 \\
1, x \geq 16
\end{array}\right\}
\end{aligned}
$$

Dengan $\mathrm{x}$ adalah nilai anggota $\mu$ sam_dekat(x), adalah derajat keanggotaan dekat, $\mu$ sam_sedang(x) adalah derajat keanggotaan sedang, dan $\mu$ sam_jauh(x) adalah derajat keanggotaan jauh pada sensor samping.

\subsubsection{Inferensi}

Tiap-tiap aturan (proposisi) pada basis pengetahuan fuzzy akan berhubungan dengan suatu relasi fuzzy. Bentuk umum dari aturan yang digunakan dalam fungsi inferensi adalah sebagai berikut :

\section{IF $x$ is A THEN $y$ is B}

Dengan $x$ dan $y$ adalah skalar, A dan B adalah himpunan fuzzy. Proposisi yang mengikuti IF disebut sebagai antesenden sedangkan proposisi yang mengikuti THEN disebut konsekuen. Proposisi ini dapat diperluas dengan menggunakan operator fuzzy seperti :

\section{$\mathrm{IF}(\mathrm{x} 1$ is $\mathrm{A1}) \mathrm{o}(\mathrm{x} 2$ is $\mathrm{A2}) \mathrm{o}(\mathrm{x} 3$ is $\mathrm{A3}) \mathrm{o} \ldots \mathrm{o}(\mathrm{xN}$ is $\mathrm{AN})$ THEN $\mathrm{y}$ is $\mathrm{B}$}

Dengan o adalah operator (misal : OR atau AND).

Berikut adalah tabel rules/aturan dalam Robot Pemadam Api pada penelitian ini.

Tabel 1. Rules Evaluation.

\begin{tabular}{|l|l|l|l|l|}
\hline No. & Sensor Kiri & Sensor Depan & Motor Kiri & Motor Kanan \\
\hline 1 & Dekat & Dekat & Pelan Arah Depan & Pelan Arah Belakang \\
\hline 2 & Dekat & Sedang & Sedang & Sedang \\
\hline 3 & Dekat & Jauh & Kencang & Kencang \\
\hline 4 & Sedang & Dekat & Pelan Arah Depan & Pelan Arah Belakang \\
\hline 5 & Sedang & Sedang & Sedang & Sedang \\
\hline 6 & Sedang & Jauh & Kencang & Kencang \\
\hline 7 & Jauh & Dekat & Pelan Arah Belakang & Pelan ke Arah Depan \\
\hline 8 & Jauh & Sedang & Kencang & Kencang \\
\hline 9 & Jauh & Jauh & Kencang & Kencang \\
\hline
\end{tabular}


Dari tabel rule di atas terdapat 9 aturan berdasarkan dari fungsi keanggotaan sensor jarak depan dan sensor jarak dinding kiri. Berikut penjelasannya :

1. Jika [sensor kiri dan sensor depan] mendeteksi jarak dalam radius dekat, maka robot akan melakukan pergerakan belok ke arah kanan dengan mekanisme driver motor kiri berputar pelan ke arah depan dan driver motor berputar pelan ke arah belakang. Dengan begitu pergerakan robot akan terkesan halus.

2. Jika [sensor kiri mendeteksi jarak radius jauh dan sensor depan mendeteksi jarak dekat], maka robot akan melakukan pergerakan belok ke arah kiri dengan mekanisme driver motor kiri berputar pelan ke arah belakang dan driver motor berputar pelan ke arah depan.

3. Jika [sensor kiri mendeteksi jarak radius dekat dan sensor depan mendeteksi jarak radius jauh] atau [sensor kiri mendeteksi jarak radius sedang dan sensor depan mendeteksi jarak radius jauh] atau [sensor kiri mendeteksi jarak radius jauh dan sensor depan mendeteksi jarak radius jauh] atau [sensor kiri mendeteksi jarak radius jauh dan sensor depan mendeteksi jarak radius sedang], maka robot akan melaju ke depan dengan putaran mesin penuh.

4. Jika [sensor kiri mendeteksi jarak radius dekat dan sensor depan mendeteksi jarak radius sedang] atau [sensor kiri mendeteksi jarak radius sedang dan sensor depan mendeteksi jarak radius sedang] maka robot tetap berjalan kedepan dengan kecepatan sedang dan bersiap-siap saat ada halangan.

5. Jika [sensor kiri mendeteksi jarak radius sedang dan sensor depan mendeteksi jarak radius dekat], maka robot akan melakukan pergerakan belok kanan dengan mekanisme driver motor kiri berputar pelan ke arah depan dan sensor kanan berputar pelan ke arah belakang.

\subsection{Defuzzyfikasi}

Tahap terakhir dari kendali fuzzy logic ini adalah defuzzyfikasi, di mana nilai fuzzy output akan diubah menjadi output. Karena menggunakan inferensi model sugeno, maka deffuzyfikasinya menggunakan singleton. "Defuzzyfikasi merupakan cara untuk mendapatkan nilai tegas dari nilai fuzzy" [4]. Fungsi keanggotaan output untuk menentukan kecepatan motor DC diperlihatkan pada Gambar 2.3 dan Gambar 2.4 berikut. 


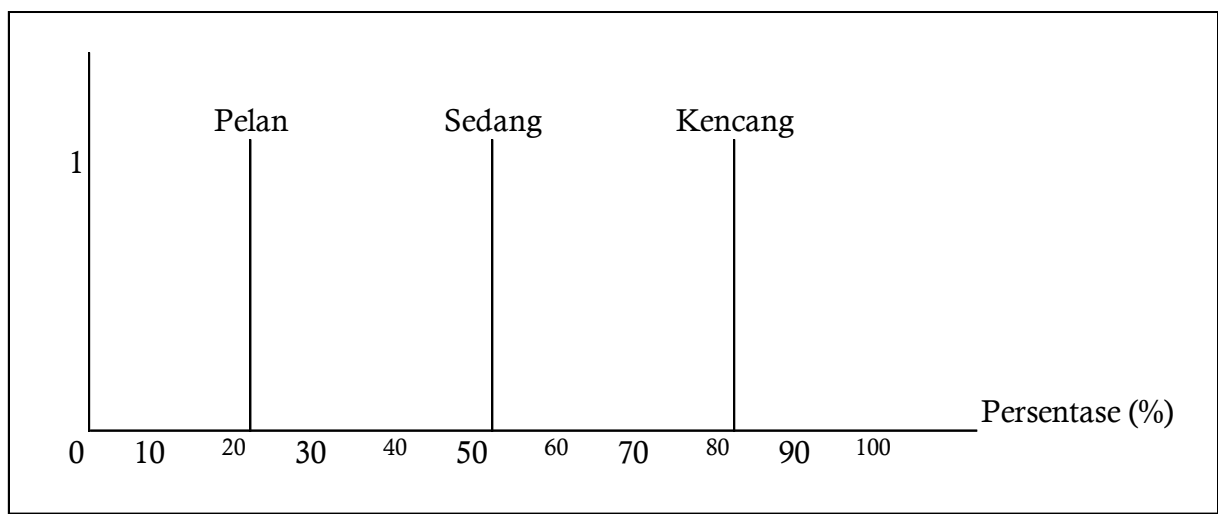

Gambar 2.3 Fungsi keanggotaan kecepatan motor kiri.

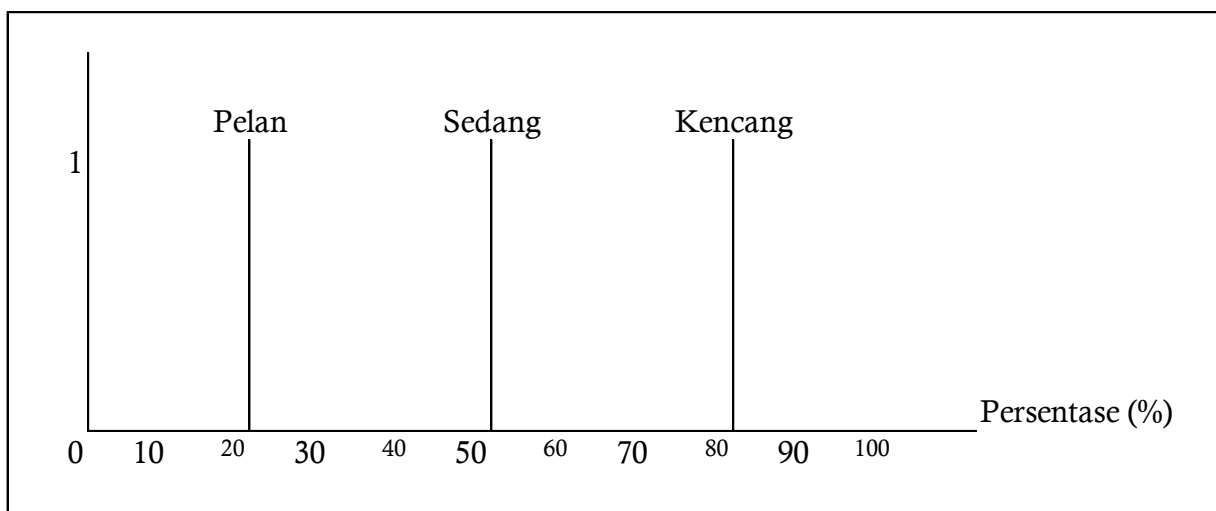

Gambar 2.4 Fungsi keanggotaan kecepatan motor kanan.

Pada fungsi keanggotaan kecepatan motor kiri dan kecepatan motor kanan terdapat 4 variabel linguistik yaitu berhenti, pelan, sedang dan kencang. Nilai domain pada masing-masing variabel didasarkan pada persentase besaran pulsa PWM yang mengatur kecepatan motor DC, pulsa minimun yang bisa diberikan adalah 0 dan maksimum 255.

Dalam projek ini penulis mengunakan metode Weight Average. "Metode Weight Average ini mengambil rata-rata dengan menggunakan nilai derajat keanggotaan dari proses komposisi fuzzy set yang sudah ditentukan" [5]. Secara matematis dapat dinyatakan sebagai berikut : 


$$
Z^{*}=\frac{\sum f(\bar{z}) \cdot \bar{z}}{\sum f(\bar{z})}
$$

Keterangan :

$$
\begin{aligned}
& Z^{*} \quad=\text { Nilai PWM yang dicari } \\
& \Sigma f(\bar{z})=\text { Hasil penjumlahan derajat keanggotaan dari proses fuzzyfikasi } \\
& \bar{z} \quad=\text { Nilai variabel yang ditentukan pada proses defuzzifikasi }
\end{aligned}
$$

\section{III.HASIL DAN PEMBAHASAN}

Pembuatan robot penjejak dinding dan pemadam api otomatis ini dilakukan dengan cara membuat rangkaian penghubung antara modul dan komponen dengan sistem yang menggunakan mikrokontroler. Kemudian memasukkan coding pada mikrokontroler tersebut sebagai acuan penggerak awal semua komponen serta mengimplementasikan rumus logika fuzzy ke dalam bahasa pemrograman yang juga dimasukkan ke dalam chip/mikrokontroler. Untuk proses pembuatan atau perakitan robot dilakukan dengan cara men-setting satu per satu semua tata letak komponen.

Di bawah ini merupakan skema cara kerja dari perancangan instalasi hardware yang dikerjakan :

1. Mikrokontroler ATmel Mega 328P, yang digunakan sebagai otak dari pengendali robot, di mana semua program atau skrip dari setiap komponen akan ditanamkan.

2. Baterai, sebagai power atau catu daya yang memberikan supply listrik untuk menyalakan robot.

3. Driver Motor L298N, sebagai komponen yang dikendalikan oleh Mikrokontroler untuk menggerakkan motor DC roda dan kipas.

4. Sensor ultrasonic dan Flame sensor, sebagai inputan di mana sensor Ultrasonik digunakan untuk mendeteksi jarak (dinding), sedangkan Flame sensor sebagai pendeteksi keberadaan api.

5. Motor DC, sebagai penggerak base robot.

6. Roda, menggunakan jenis roda tracker yang dapat lebih leluasa bergerak pada medan yang sulit dibandingkan dengan roda biasa. 


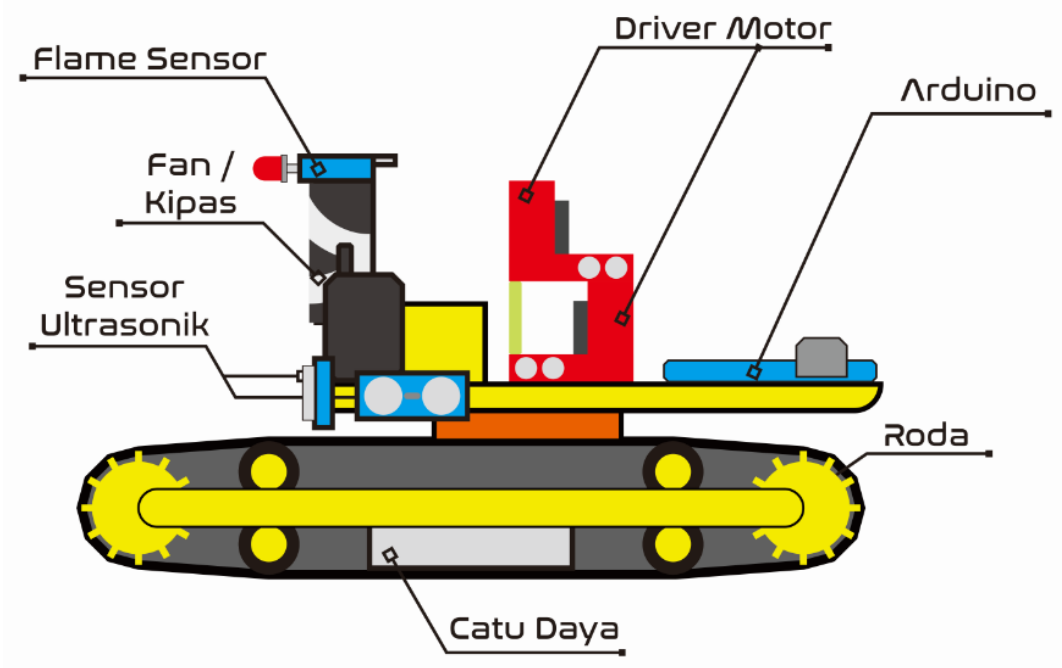

Gambar 3.1 Gambaran perancangan mekanikal dan sistem pada robot.

\subsection{Diagram Blok}

Dalam perancangan sistem ini akan dijelaskan cara kerja alat melalui diagram blok berikut, untuk memudahkan dalam mempelajari cara kerja komponen-komponen yang akan digunakan dalam projek ini ditunjukan pada gambar 3.2.

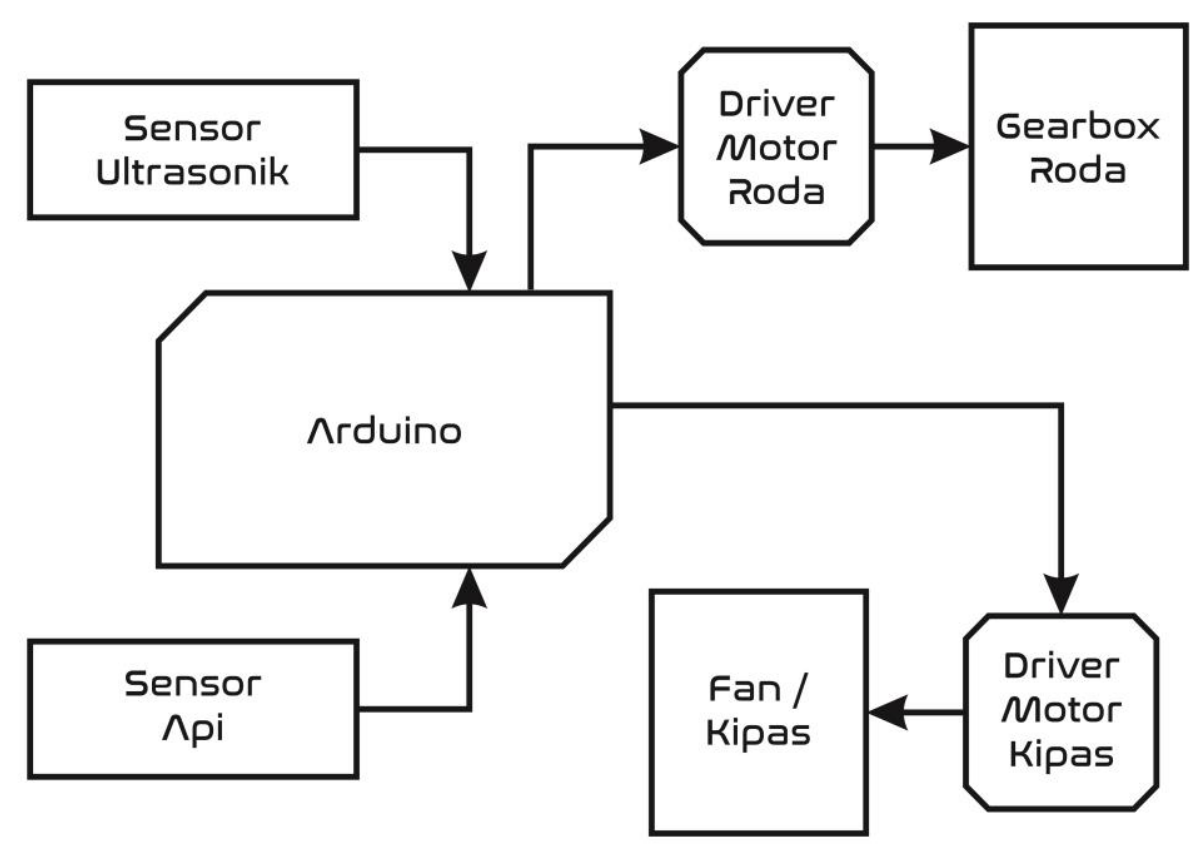

Gambar 3.2 Diagram Blok Sistem Robot.

Berdasarkan diagram blok di atas, terdapat dua buah sensor yaitu sensor ultrasonik untuk mencari data jarak halangan di depan robot dan flame sensor untuk mencari data adanya api di depan robot. Kemudian kedua sensor tersebut memberikan data yang akan 
diproses dalam mikrokontroler. Setelah menerima inputan data tersebut, mikrokontroler memberikan perintah ke driver motor roda yang diteruskan ke gearbox untuk menjalankan robot dan ke driver motor kipas untuk menghidupkan fan/kipas sebagai mekanisme pemadaman api.

\subsection{Perancangan Flowchart Diagram}

Flowchart pada gambar di bawah ini (Gambar 7.) merupakan fungsi dasar dari sistem yang akan dibuat. Tahap awal adalah ketika robot diaktifkan, maka sensor ultrasonik akan mencari dinding terdekat yang ada di sekitar robot. Jika [sensor kiri dan sensor depan] mendeteksi jarak dalam radius dekat, maka robot akan melakukan pergerakan belok ke arah kanan dengan mekanisme driver motor kiri berputar pelan dan driver motor kanan berhenti. Dengan begitu pergerakan robot akan terkesan halus. Lalu jika [sensor kiri mendeteksi jarak radius jauh dan sensor depan mendeteksi jarak dekat], maka robot akan melakukan pergerakan belok ke arah kiri dengan mekanisme driver motor kiri berhenti dan driver motor kanan berputar pelan. Kemudian jika [sensor kiri mendeteksi jarak radius dekat dan sensor depan mendeteksi jarak radius sedang] atau [sensor kiri mendeteksi jarak radius sedang dan sensor depan mendeteksi jarak radius dekat], maka robot tetap melaju namun tidak dengan kecepatan penuh, berjaga-jaga dan bersiap-siap jika di depan terdapat halangan. Selain semua kondisi di atas, maka robot akan melaju ke depan dengan putaran mesin penuh.

Rancangan sistem yang dimodelkan dalam bentuk flowchart diagram adalah sebagai berikut : 


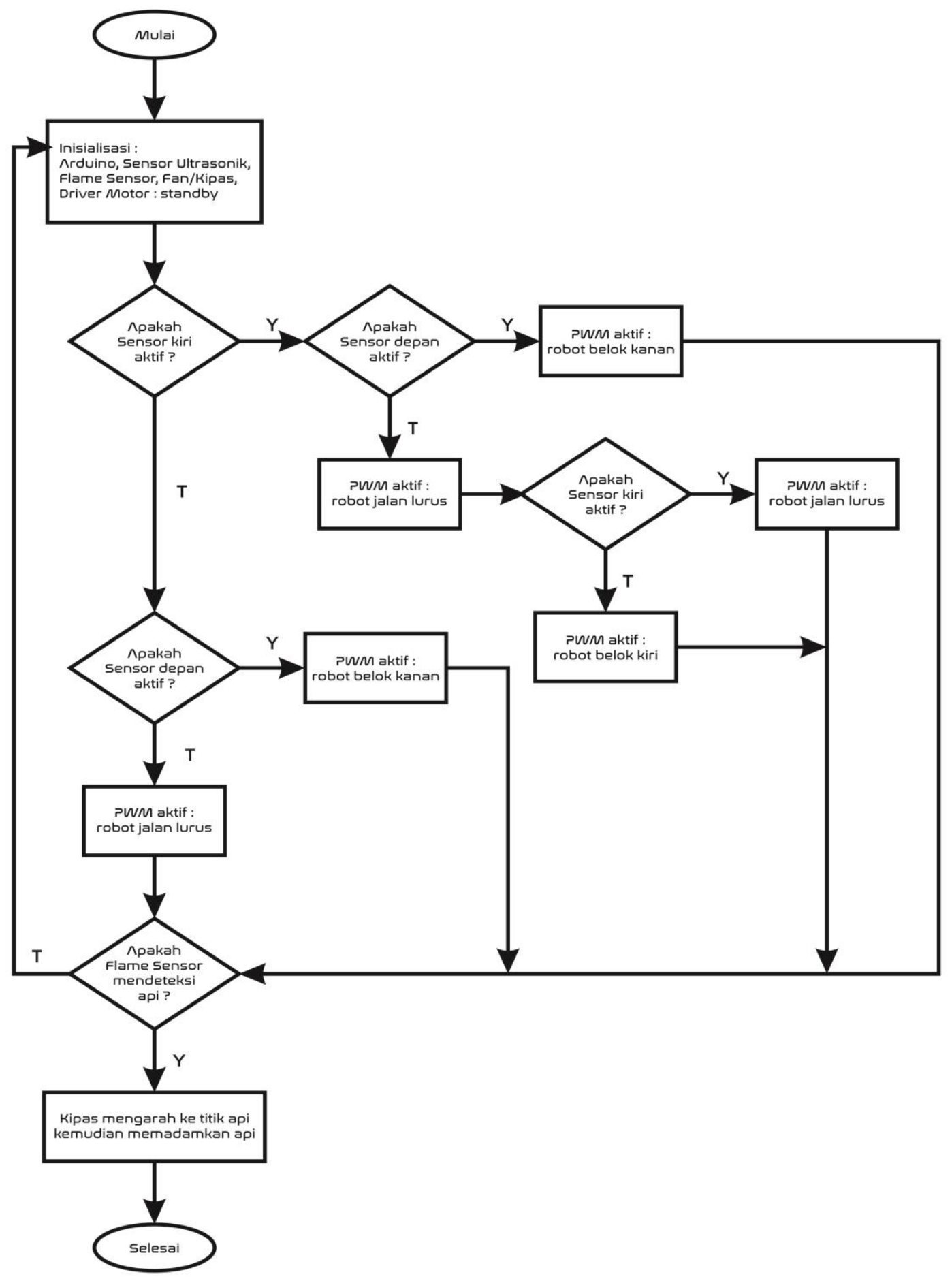

Gambar 3.3 Gambar Diagram Alir Sistem Robot. 


\section{KESIMPULAN DAN SARAN}

Setelah melakukan berbagai tahapan perancangan dan pemasangan komponen pada robot, selanjutnya adalah melakukan serangkaian uji coba pada masing - masing blok rangkaian yang bertujuan untuk mendapatkan hasil yang sesuai. "Dengan menggunakan fasilitas serial monitor yang terdapat pada software Arduino IDE maka akan memudahkan pembacaan data yang diambil dari sensor dan yang masuk ke sistem arduino" [6]. Adapun pembahasan hasil uji coba agar lebih jelas dan dapat dipahami mengenai beberapa ragkaian sistem yang dipakai, dapat dilihat pada sub bab berikut :

Pengujian Sensor Api dan Arduino

Pengujian ini dimaksudkan untuk mengetahui apakah sensor dapat menangkap radiasi api di depan robot, yang nantinya data tersebut akan dikirim ke arduino. Data yang sudah dikonversi menjadi angka ini akan menjadi masukan dan diproses oleh sistem Arduino untuk menjadi pemicu kapan waktunya kipas harus menyala atau tetap dalam keadaan off.

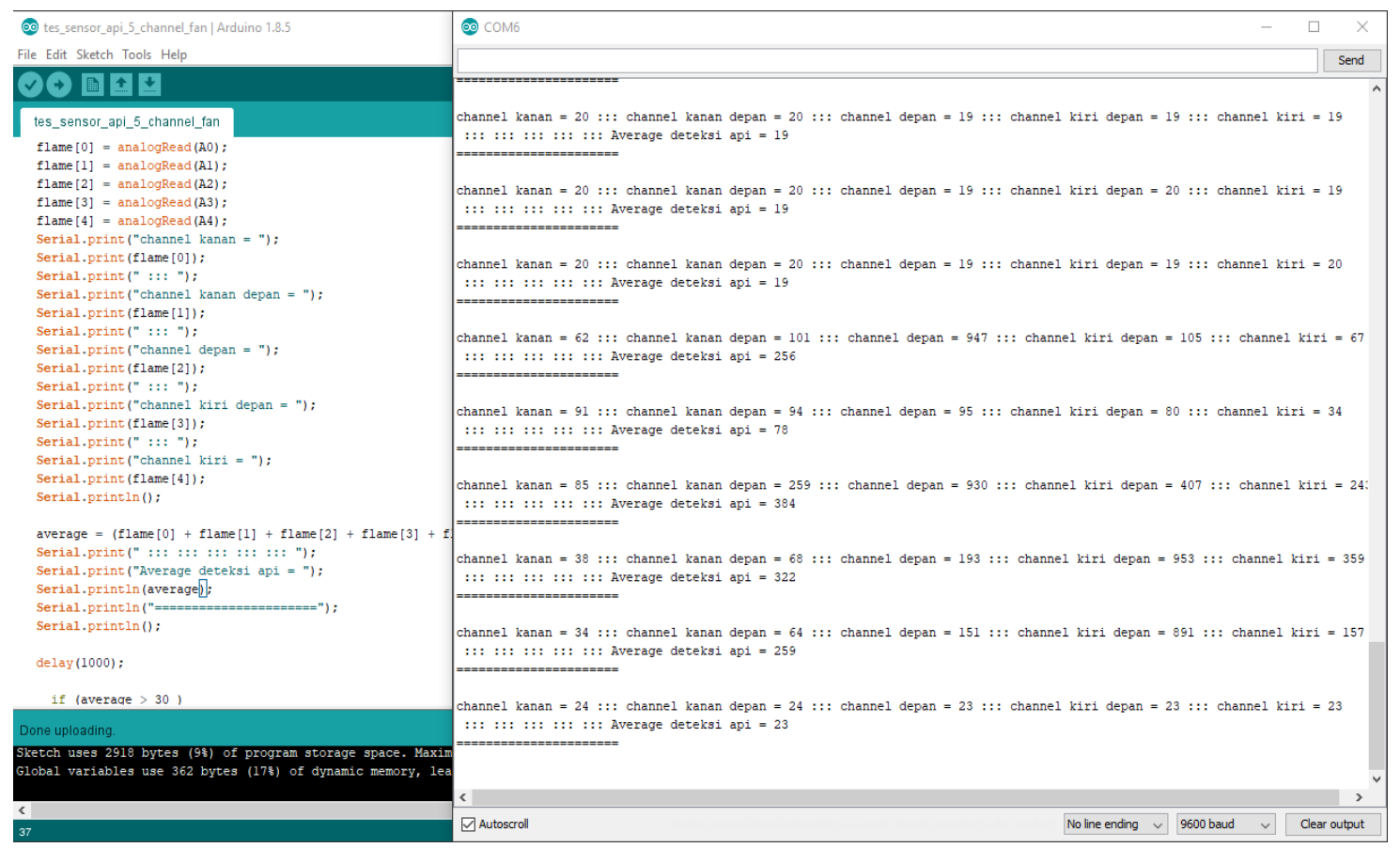

Gambar 4.1 Indikasi arduino dapat menangkap data radiasi api dari flame sensor melalui serial monitor. 


\subsection{Pengujian Sensor Ultrasonik dan Arduino}

Melalui pengujian ini akan diketahui apakah sensor dapat menangkap data jarak di depan dan di samping robot, yang nantinya data tersebut akan dikirim ke arduino. Data yang sudah dikonversi menjadi angka ini akan menjadi masukan dan diproses oleh sistem Arduino untuk menjadi acuan pergerakan robot apakah harus berjalan maju atau berbelok.

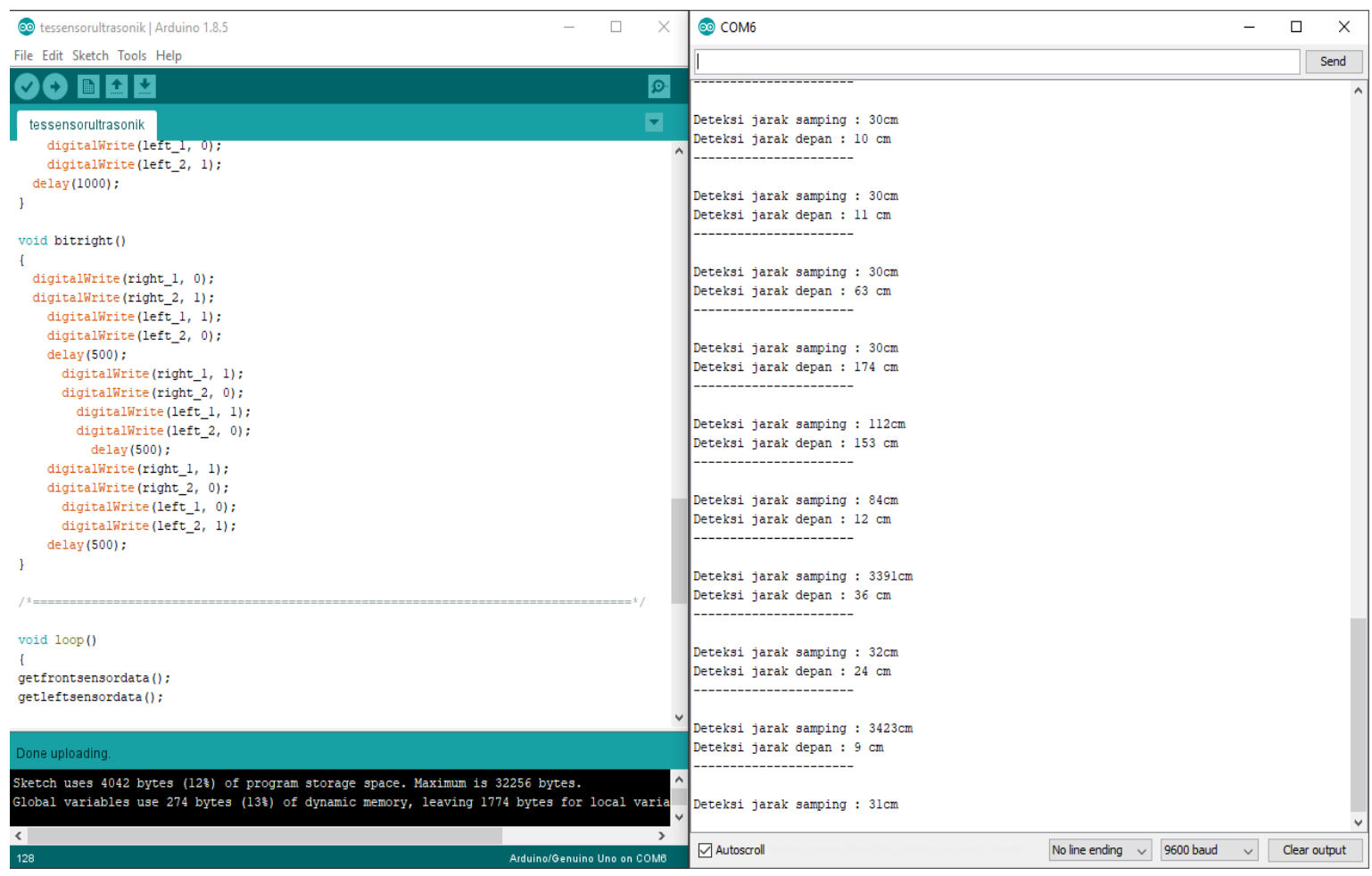

\section{Gambar 4.2 Indikasi arduino dapat menangkap data jarak dari sensor ultrasonik melalui serial monitor.}

\subsection{Simulasi Pengujian Pergerakan dan Kipas Robot}

Pengujian ini sebagai simulasi yang tidak bisa diperlihatkan melalui penulisan tentang pergerakan robot maju, berhenti, belok kanan dan belok kiri, serta menyalatidaknya kipas yang menjadi mekanisme pemadaman api ketika flame sensor mendeteksi api di sekitar robot. 


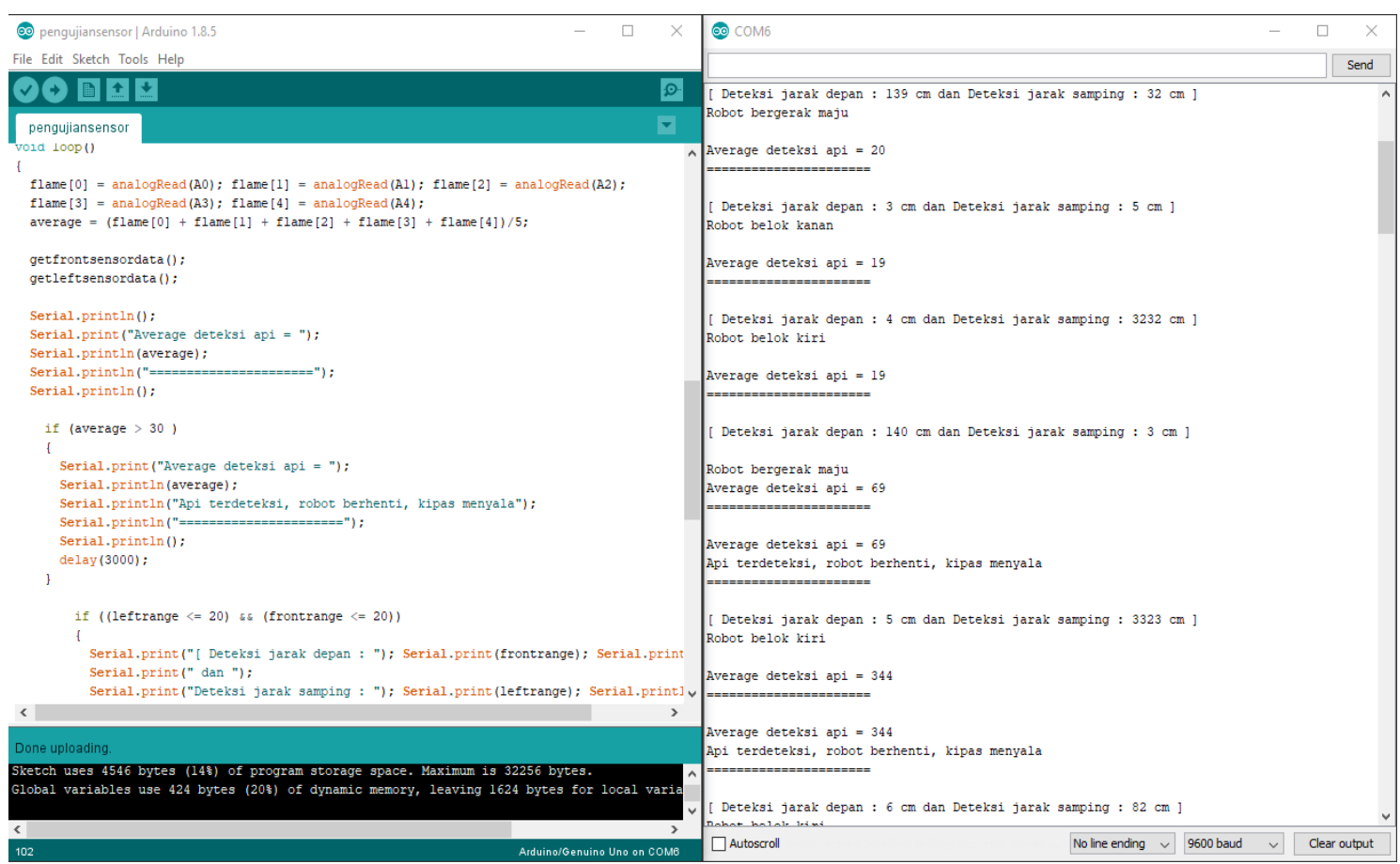

Gambar 4.3 Simulasi pergerakan robot dan pendeteksian api melalui serial monitor.

\subsection{Hasil Pengujian Dan Kesimpulan}

Setelah dilakukan pengujian pada robot telah didapat kesimpulan sebagai berikut:

1. Logika fuzzy logic yang diterapkan pada coding sistem dapat berjalan lancar sehingga robot dapat bergerak dengan baik ke arah maju, belok kanan, belok kiri dan berhenti sesuai dengan rule yang telah ditentukan.

2. Logika fuzzy logic juga digunakan pada perhitungan kecepatan putaran roda robot, sehingga robot dapat bergerak pelan atau cepat sesuai dengan rule yang telah ditentukan.

3. Robot mampu mendeteksi dinding pada jarak kisaran $20 \mathrm{~cm}$ sesuai seperti yang telah diinputkan pada program.

4. Robot mampu mendeteksi api dan menjalankan perintah menyalakan atau mematikan kipas dengan baik.

Dalam proses pembuatan sistem dan mekanisme robot simulasi pemadaman api ini terdapat beberapa hal yang dapat disimpulkan, antara lain :

1. Dalam pengujian, robot dapat bergerak mengikuti alur dinding dan dapat berhenti untuk memadamkan api saat sensor mendeteksi adanya api.

2. Terkadang dalam pergerakan robot masih memiliki jeda saat memproses perintah belok, berhenti dan memadamkan api karena coding masih menggunakan metode delay. 
3. Kipas dapat bekerja dengan tepat pada waktu flame sensor mendeteksi api, namun terkadang kekuatan angin yang dihasilkan kipas tidak dapat memadamkan api dengan cepat.

4. Terkadang robot tidak dapat berjalan lurus dalam artian berjalan serong. Hal ini bukanlah kesalahan dari sistem atau programnya, namun dikarenakan chassis/body robot tidak stabil (terbuat dari plastik).

Berikut beberapa saran yang dapat penulis berikan untuk pengembangan yang lebih baik pada penelitian selanjutnya, yaitu :

1. Menambahkan sensor ultrasonik pada bagian kanan dan belakang agar robot memiliki perintah atau memiliki tingkat pengambilan keputusan lebih banyak untuk dapat bergerak maju dan mundur juga, tidak hanya maju, belok kanan dan belok kiri.

2. Gunakan kipas yang dapat menghasilkan tekanan angin yang lebih besar agar dapat memadamkan api dengan lebih cepat.

3. Menggunakan sensor ultrasonik dan sensor api dengan tipe/kualitas yang lebih baik agar sistem bekerja dengan lebih maksimal.

4. Menggunakan chassis yang lebih kuat/solid agar robot dapat berjalan lebih stabil. 


\section{DAFTAR PUSTAKA}

[1]. Silitonga, Y. F. (2014). Perancangan Robot Mobile Penjejak Dinding Koridor Dengan Kendali Logika Fuzzy. Jurnal Penelitian Jurusan Teknik Elektronika Politeknik Negeri Batam.

[2]. Pungky Eka Sasmita, T. A. (2013). Kontrol Penjejak Pada Robot Pemadam Api Menggunakan Sistem Pengindera Api Dan Posisi Jarak Dengan Metode Fuzzy Logic. Jurnal Penelitian Jurusan Teknik Elektro FTI - ITS.

[3]. Ari Azhar, K. D. (2015). Perancangan Fuzzy Logic Model Sugeno untuk Wall Tracking pada Robot Pemadam Api. Jurnal Politeknik Caltex Riau, 4.

[4]. Ramdani, T. (2014, Februari 26). Pengertian Metode Dan Metodologi Penelitian. Retrieved Februari 23, 2018, from slideshare.net: https://www.slideshare.net/tri_ramdani/pengertian-metode-danmetodologi-penelitian.

[5]. Umam, F. (2013). Pengembangan Sistem Kendali Pergerakan Autonomous Mobile Robot Untuk Mendapatkan Jalur Bebas Hambatan Menggunakan Fuzzy Logic Controller. Jurnal Ilmiah Mikrotek Vol. 1, No.1, 36.

[6]. Aji, S. (2016, Agustus 11). Menangani Sensor Api (Flame Detektor) Dengan Arduino. Retrieved Januari 02, 2018, from saptaji.com: http://saptaji.com/2016/08/11/menangani-sensor-api-flame-detectordengan-arduino/ 